\title{
The Effectiveness of Benchmarking as a Organizational Transformation Strategy in Higher Education institutions in South Africa
}

\author{
Ronald James Odora (Ph.D) \\ Department of Mathematics, Science and Technology Education \\ School of Education, Faculty of Humanities, University of Limpopo, South Africa \\ E-mail: rodora@cut.ac.za
}

\section{Doi:10.5901/mjss.2014.v5n1p521}

\section{Abstract}

Higher education institutions in South Africa are increasingly embracing various benchmarking strategies to achieve their organizational transformation agenda. While there is evidence that suggests many universities have adopted different types of benchmarking strategies, very little is known of the impact of such strategies. This case study examined the impact of benchmarking in Higher Education in South Africa with special reference to Central University of Technology. A total of 62 lecturers participated in the study. Data for the study was collected using questionnaire. And analyzed used SPSS software. The study reveals many staff members are familiar with benchmarking and therefore it is not widely practiced. The findings also highlight some disincentives and problems associated with the use of benchmarking as a quality assurance tool at Central University of Technology. On a positive note, the study reveals that over $50 \%$ of lecturers agree that benchmarking offer a number of benefits for higher education and therefore can play a great role in achieving organizational transformation strategy in Higher Education institutions in South Africa

Keywords: effectiveness, benchmarking, organizational transformation, strategy, higher education, South Africa.

\section{Introduction}

Higher Education institutions worldwide are undergoing a number of organizational transformations brought about by increased competition, demands for accountability and impact of globalization (Aslette, 2004). Coupled with new funding provision models, higher public expectations over what universities should be delivering, increasing parental concerns about the quality of education, greater emphasis on university ratings, increasing class sizes, diverse student population, equity issues, increasing competitions and demands for accountability higher education worldwide are changing the way in they operate (Oketch, 2009; Weeks, 2000). As part of accountability, most universities are being asked to present institutional effectiveness to the general public.

Besides, "universities are expected to have goals and plans to attain them, as well as mechanisms for evaluating their progress (Ramirez, 2010:43). Hence, several types of tools for assessing quality in higher education have been developed recently based on quality assurance mechanism and rankings, which emphasize output monitoring and measurements and systems of accountability and auditing has become more popular worldwide (Marginson, 2007, Salmi and Saroyan, 2007). Among the improvement strategies and techniques such as Total Quality Management (TQM), Continuous Quality Improvement (CQI), and Business Process Reengineering (BPR), benchmarking has emerged as a useful, easily understood, and effective tool for staying competitive (Alstete, 1995., Sharma, 2009., Nicholson, 2011., Rashmi, Anithashree Angappa and Gunasekaran, 2010).

\subsection{Benchmarking: definitions and concepts}

The term "benchmarking" as it is commonly known come from the verb "benchmark". The term refers to a point of reference to make comparison, usually with a connotation that it is a good basic standard to achieve (Stella and Woodhouse, 2007). Therefore, in its simplest definition, benchmarking is the process of identifying benchmarks that enables comparison of inputs, processes or outputs between institutions (or parts of institutions) or within a single institution over time.

Benchmarking, although seems a new concept, is a very old one. Amongst the individuals, Francis Lowell and Henry Ford are the pioneers who have given practical fillip to benchmarking (Mehraj and Shah, 2012). It may be stated 
here that Xerox, IBM and Motorala are the early prominent companies that have applied benchmarking in different spheres within their industries. Through benchmarking, these industries have succeeded to raise the quality of their products and market share as well (Bhat, 2000., Lutfullayev, 2001).

Thus, benchmarking as practiced in business and industry is all about comparing practices and performance with competitors in order to identify own strengths and weaknesses. Alstete (1996) maintains that the central purpose of benchmarking in industry is to provide managers with an external point of reference or standard of evaluating the quality and cost of their organization's internal activities, practices and processes. Within the business sector, benchmarking is seen as effective way to ensure continuous improvement or progress towards strategic goals and organizational priorities. While (Camp, 1995), states "benchmarking must come to mean learning form others". It is a process of moving from where we are and where we want to go. Bench-marking is somewhat different from Benchmark.

Since the term 'benchmarking' became a common vocabulary in Higher education it has been given a wide range of meanings and concepts. According to UNESCO (1998) benchmarking is a standardized method for collecting and reporting critical operational data in a way that enables relevant comparisons among the performances of different organizations or programmes, usually with a view to establishing good practice, diagnosing problems in performance, and identifying areas of strength. Benchmarking gives the organization (or the programme) the external references and the best practices on which to base its evaluation and to design its working processes.

Vlãsceanu et al., (2004:25) defines benchmarking as:

a diagnostic instrument (an aid to judgments on quality), a self-improvement tool (a quality management/quality assurance tool) allowing organizations (programmes) to compare themselves with others regarding some aspects of performance, with a view to finding ways to improve current performance, an open and collaborative evaluation of services and processes with the aim of learning from good practices, a method of teaching an institution how to improve, and an on-going, systematically oriented process of continuously comparing and measuring the work processes of one organization with those of others by bringing an external focus on internal activities'.

According to Vlãsceanu et al., (2004:26-28) benchmarking implies specific steps and structured procedures and that there are different types of benchmarking depending on what data is compared.

As for Higher Education Quality Council (HEQC) (2004) benchmarking is:

a process by which an institution, programme, faculty, school, or any other relevant unit evaluates and compares itself in chosen areas against internal and external, national and international reference points, for the purposes of monitoring and improvement (HEQC, 2004, p. 26).

Jackson and Lund (2000) suggested a working definition for benchmarking in UK higher education which encompasses both development and accountability. It states: '...a process to facilitate the systematic comparison and evaluation of practice, process and performance to aid improvement and regulation.' They add that benchmarking is: '...first and foremost, a learning process structured so as to enable those engaging in the process to compare their services-activities-processes-products-results in order to identify their comparative strengths and weaknesses as a basis for self-improvement and/or self-regulation. According to Jackson and Lund (2000) benchmarking offers a way of not only doing the same things better but of discovering 'new, better and smarter' ways of doing things and in the process of discovery, understanding why they are better or smarter.'

Other definitions of benchmarking are couched around the context and activities (processes) through which it is carried out. This is based on the believe that it is only through an understanding of how inputs are transformed into outputs that the attainment of superior results can be pursued effectively. Thus to quote Camp (1995), benchmarking is:

an integral part of planning and ongoing review process to ensure a focus on external environment and to strengthen the use of factual information in developing plans. Benchmarking is used to improve performance by understanding the methods and practices required to achieve world-class performance level. Benchmarking's primary objective is to understand those practices that will provide a competitive advantage; target setting is secondary (Camp, 1995:15)

All the above definitions and elaborations of benchmarking identify benchmarking as a tool, a technique for continuous improvements in sectoral operations to gain and maintain competitive advantage. The process involves comparing performance between two or more entities, and progressively working towards the improvement of quality of services rendered by the organization that undertakes the benchmarking process.

A review of the literature indicates that there can be a number of reasons for institutions to embark on 
benchmarking. Benchmarking is found to increase the potential for improvement in numerous ways, as it:

- provides a systematic approach to quality improvement;

- establishes the extent of improvement required

- bring an external focus to internal activities

- uses existing knowledge about the effectiveness of a particular process

- identifies new ideas and innovative approaches

- demystifies, encourages and provides a framework for change

- enables the incorporation of 'best practice' into one's organization

- decreases subjectivities in decision-making by basing it on hard data

- helps create learning organization, and

- promote contacts and networks (Scott, 2011: 2-3).

By highlighting problem areas as well as potential for improvement, benchmarking also provide incentives to change and assist in the setting of target goals. Furthermore, it emphasizes on understanding the process underlying successful practice, makes it useful tool in establishing plans and strategies for achieving these goals. In summary, benchmarking can be viewed as a comprehensive method for improving organizational practices; it highlights areas needing improvement, it provides objectives, data to illustrate the need for change in these areas, and it lead to the formulation of plans and initiatives for bringing about the required improvements (Alstete, 1995).

Participating in benchmarking has been found to promote a culture of thinking about quality, assessing one's own performance and taking responsibility for it (Obara et al, 2011). Practitioners in higher education institutions in the UK have found that benchmarking helps overcome resistance to change, provides a structure for external evaluation, and creates new networks of communication between schools where valuable information and experiences can be shared (AACSB 1994).

\subsection{Benchmarking in Higher Education in South Africa}

As a wider initiative to develop nationally agreed indicators and performance measures, several benchmarking strategies have been developed and adopted by the South Africa government. Since 1994 the South Africa government's focus on education has been to improve the quality of teaching and learning at all levels of education. This position is reaffirmed by the creation of a number of quality assurance councils. The Quality Councils are responsible for the development, implementation and quality assurance of their respective qualifications framework, qualifications and part qualifications, and the learning and assessment provisions thereof (SAQA Report, 2007). The Higher Education Quality Committee (HEQC) mandates are to (i) promote quality assurance in higher education; (ii) audit the quality assurance mechanisms of Higher institutions; (iii) accredit programmes of Higher education (More and Lan Lin, 2009). Higher Education Quality Committee (HEQC) as an accrediting body recognizes the value of an analytical and self-critical process. Through the self-assessment report, the on-site visit team tries to understand and evaluate the institution or the programme. Then based on the report of the institution and the programme and the recommendations of the review ream, the accrediting body make decision and likely give advice to the government (Martin and Stela, 2007). Other Quality Assurance Councils include: SAQA - benchmark external qualifications with South African qualifications; Quality Council for Trades and Occupations (QCTO) - is responsible for quality assurance of the occupations and trades offered by skills development providers and employers and workplaces and Quality Council for General and Further Education and Training (Umalusi).

In oder to meet the stated set quality standards set out by varous quality assurance bodies it has become imperative for universities to adopt two or more of the following benchmaking practices based on Camp's typology (Camp,1989, 1995).

Internal - This is a comparision among similar operation within one's own unit or department

Competitive - This is a comparison to the best of the direct competitors

Functional - This is a comparison of methods to companies with similar processes in the same function outside one;s industry

Generic process - This is a comparison of work processes to others who have innovative, examplar work processes (Camp, 1995:16).

Like other universities around the world, internal benchmarking in which comparisons are made of the performance of different departments, campuses or sites within a university tend to be widely used in South Africa. As reported by Coopers and Lybrand (1994), internal benchmarking is generally preferred because of the complexities of establishing partnerships particularly with competitors. They argues that internal benchmarking can draw on existing 
sources of data, collected under relatively comparable circumstances and with greater cost-effectiveness. Alstete (1996) content that the methodology used is relatively open and collaborative and that schemes may be run by the institutions themselves on a collective basis, although in other cases a central agency or consultant may administer the scheme in order to ensure continuity and sufficient momentum.

While the higher education sector is in general positive about the benefits of benchmarking and has embraced it as a useful quality assurance tool, there are critics who believe this type of quality assurance mechanism is not applicability to higher education. They argue that benchmarking is merely a strategy for marginally improving existing processes, that it is applicable only to administrative processes (or only to teaching practices), is a euphemism for copying, is lacking innovation, or that it can expose institutional weaknesses (Brigham 1995; Dale 1995).

Another area of contention among the practitioners in higher education is the lack of a commonly acceptable definition of benchmarking. Thus, what is understood as 'benchmarking' varies considerably between both different approaches and different practitioners, thus causing problems to institutions investigating the subject for the first time. These difficulties of nomenclature go well beyond what may be ultimately sterile attempts to find acceptable definitions for their own sake, and instead reveal considerable cultural and methodological differences of approach which underpin how benchmarking is implemented (Stella and Woodhouse, 2002).

Meade (1997) identifies drawbacks of benchmarking as possible restrictive nature of the focused on current practices and standards, and the temptation for organizations to be followers rather than leaders. In his study of benchmarking in higher education in Australia, Weeks (2000) reported that some staff saw their colleagues from other departments or faculties as competitors and did not want to share information with them. Others saw the process as no more than the normal visits made by academics to each other's areas of specialization. Holloway et al. (1997) are of the view that while benchmarking may be regarded as a 'good thing' by education practitioners, statutory and professional bodies, there is evidence to suggest that in some instances the costs may outweigh the benefits.

Although there is widespread use of benchmarking in most higher education institutions in South Africa, studies to determine impact of such quality assurance strategies is still scanty. Given the specialist nature of the journal, this may seem surprising but reflects the general paucity of significant research into the impact of benchmarking processes in higher education institutions. The aim of this study was to establish the impact of internal benchmarking at Central University of Technology.

In achieving this goal, the study sought to answer the followings questions:

- What are the reasons for benchmarking in higher education institutions?

- What are the perceived benefits of benchmarking in higher education institutions?

- Are there any disincentives and/or problems associated with benchmarking in higher education institutions?

\section{Research Method}

\subsection{Research design}

The case study was based on quantitative research method and employed exploratory and descriptive survey research design to describe factors affecting benchmarking strategies at Central University of Technology, South Africa. The aim of the study was examine benchmarking processes used in various faculties and its impact on the mission and vision of the university. The study was limited geographically to Central University of Technology, Free State. The subjects for this study were lecturers selected from four faculties. From the list of the lecturers in that were relevant to this study, 80 lecturers were selected using simple random selection. A total of 62 lecturers answered the self-administered questionnaire. This sample size was estimated to result in a sampling error of plus or minus $8 \%$. Due to the nature of the survey data gathering technique, associated costs, and time, the sample size of 80 was judged to be acceptable.

\subsection{Instrument of the study}

The instrument used in this study was developed by the researchers and tested for validity and reliability. The instrument was a semi-structure questionnaire consisting of closed and open questions/statements intended to solicit views of purposely sampled lecturers from Central University of Technology. All questions was based on a five-point Likert rating scale of 1 to 5 where $1=$ Not observed, 2=weak. 3=average, 4=good, and 5=outstanding. The questions were divided into two main sections: section one dealt with biographical information about the students; section two covered variables relating to apprenticeship training, entrepreneurship within course offerings, perceptions of students regarding course 
relevance to employment.

\subsection{Data collection procedures}

Contact was made with lecturers from the faculty of Management Sciences, Humanities, Engineering and Health and Environmental Sciences. The details of the study were explained and copies of the questionnaire made available. All the lecturers who were contacted agreed to answer the questionnaire. The research questionnaire was delivered to lecturers by the researchers and collected after it was completed.

\subsection{Data analysis procedures}

The independent variable in the study was benchmarking. The dependent variables were reasons, benefits and disincentives and problems for benchmarking. The percentage of lecturers" responses were computed to see the level of their agreement. The researcher computed the percentage of the respondents for all the items under dependent variable using Statistical Package for Social Science (SPSS).

\subsection{Ethical issues}

Respondents' consent was obtained after the purpose of the study was explained to them, and informed that their participation was voluntary. Confidentiality and anonymity of the respondents and their associated institutions was also ensured.

\section{Findings}

\subsection{Reasons for benchmarking}

The first aim of the study was to determine reasons for benchmarking among academic staff at the university. Table 1 presents the percentage of respondents for each reason presented.

Table 1: Reasons for benchmarking $(n=62)$

\begin{tabular}{|c|c|c|c|c|c|}
\hline & $\begin{array}{c}\% \\
\text { Strongly } \\
\text { agree }\end{array}$ & $\begin{array}{c}\% \\
\text { Agree }\end{array}$ & $\begin{array}{c}\% \\
\text { Disagree }\end{array}$ & $\begin{array}{c}\% \\
\text { Strongly } \\
\text { disagree }\end{array}$ & $\begin{array}{c}\% \\
\text { Not } \\
\text { sure }\end{array}$ \\
\hline $\begin{array}{l}\text { I always use benchmarking to find how I am performing compared to } \\
\text { other academic staff within our programme/department. }\end{array}$ & 16.1 & 17.7 & 48.4 & 9.7 & 8.1 \\
\hline $\begin{array}{l}\text { I always use benchmarking to source 'best practices' in higher } \\
\text { education and elsewhere. }\end{array}$ & 20.0 & 22.6 & 43.5 & 8.1 & 5.8 \\
\hline $\begin{array}{l}\text { I always use benchmarking to align my activities with the vision and } \\
\text { mission of the university. }\end{array}$ & 8.1 & 16.1 & 19.4 & 53.2 & 3.2 \\
\hline I often use benchmarking in for the purpose of getting promotion. & 24.2 & 24.2 & 32.3 & 12.9 & 6.1 \\
\hline I always use benchmarking for search of excellence & 33.9 & 29.0 & 19.4 & 12.9 & 4.8 \\
\hline
\end{tabular}

On a scale between 0 and 5, where 0 meant not sure and 5 meant strongly agree, $48.4 \%$ of respondents strongly disagreed that they did not use benchmarking to find how they were performing compared to other staff within their programme/department. Over $50 \%$ of the respondents also disagreed to the use benchmarking as a source 'best practices. Fifty three percent (53\%) disagreed that they always use benchmarking to align my activities with the vision and mission of the university. Thirty two percent (32\%) disagreed that they often use benchmarking in for the purpose of getting promotion. Thirty four percent (34\%) agreed that they often use benchmarking for search of excellence.

\subsection{Benefits for benchmarking}

The second aim of the study was to determine the perceptions of academic staff regarding the benefits for benchmarking in higher education. Table 2 presents the percentage of respondents for each benefit presented. 
Table 2:.Benefits for benchmarking $(n=62)$

\begin{tabular}{|c|c|c|c|c|c|}
\hline$N=62$ & $\begin{array}{c}\% \\
\text { Strongly } \\
\text { agree }\end{array}$ & $\begin{array}{c}\% \\
\text { Agree }\end{array}$ & $\begin{array}{c}\% \\
\text { Disagree }\end{array}$ & $\begin{array}{c}\% \\
\text { Strongly } \\
\text { disagree }\end{array}$ & $\begin{array}{c}\% \\
\text { Not } \\
\text { sure }\end{array}$ \\
\hline $\begin{array}{l}\text { Benchmarking provides a systematic approach to quality } \\
\text { improvement }\end{array}$ & 32.3 & 54.8 & 3.2 & 3.2 & 6.5 \\
\hline Benchmarking establishes the extent of improvement required & 32.3 & 53.2 & 9.7 & 3.2 & 1.6 \\
\hline Benchmarking bring an external focus to internal activities & 41.9 & 33.9 & 16.1 & 8.1 & - \\
\hline $\begin{array}{l}\text { Benchmarking uses existing knowledge about the effectiveness } \\
\text { of a particular process }\end{array}$ & 37.1 & 40.3 & 14.5 & 6.5 & 1.6 \\
\hline Benchmarking identifies new ideas and innovative approaches & 30.6 & 46.8 & 17.7 & 3.2 & 1.6 \\
\hline $\begin{array}{l}\text { Benchmarking demystifies, encourages and provides a } \\
\text { framework for change }\end{array}$ & 30.6 & 41.9 & 14.5 & 6.5 & 6.5 \\
\hline $\begin{array}{l}\text { Benchmarking enables the incorporation of 'best practice' into } \\
\text { one's organization }\end{array}$ & 29.0 & 50.0 & 14.5 & 1.6 & 4.8 \\
\hline $\begin{array}{l}\text { Benchmarking decreases subjectivities in decision-making by } \\
\text { basing it on hard data }\end{array}$ & 32.3 & 46.8 & 12.9 & 1.6 & 6.5 \\
\hline Benchmarking promotes contacts and networks & 33.9 & 58.1 & 4.8 & 1.6 & 1.6 \\
\hline
\end{tabular}

The survey revealed that the majority of the respondents (over 50\%) agreed that benchmarking has a number of benefits for higher education. Fifty five (55\%) agreed that benchmarking provides a systematic approach to quality improvement, $53 \%$ agreed that benchmarking establishes the extent of improvement required, 50\% agreed that Benchmarking enables the incorporation of 'best practice' into one's organization and 58\% agreed that Benchmarking promotes contacts and networks.

\subsection{Disincentives and problems}

The third aim of the study was to determine the perceptions of academic staff regarding some disincentives and problems associated with the use of benchmarking as a quality assurance tool in higher education. Table 3 presents the percentage of respondents for each benefit presented.

Table 3: Disincentives and problems $(n=62)$

\begin{tabular}{|c|c|c|c|c|c|}
\hline & $\begin{array}{c}\% \\
\text { Strongly } \\
\text { agree }\end{array}$ & $\begin{array}{c}\% \\
\text { Agree }\end{array}$ & $\begin{array}{c}\% \\
\text { Disagree }\end{array}$ & $\begin{array}{c}\% \\
\text { Strongly } \\
\text { disagree }\end{array}$ & $\begin{array}{c}\% \\
\text { Not } \\
\text { sure }\end{array}$ \\
\hline $\begin{array}{l}\text { I am not aware of any benchmarking activities that exist in our } \\
\text { programme/department. }\end{array}$ & 21.0 & 40.3 & 21.0 & 17.7 & - \\
\hline $\begin{array}{l}\text { I am not involved in many benchmarking activity in my } \\
\text { department/school. }\end{array}$ & 12.9 & 45.2 & 19.4 & 19.4 & 3.2 \\
\hline $\begin{array}{l}\text { Benchmarking is more effective if it is initiated at grass root level rather } \\
\text { than imposed by the organization. }\end{array}$ & 17.7 & 41.9 & 25.8 & 9.7 & 4.8 \\
\hline $\begin{array}{l}\text { Benchmarking alone does not lead to quality of instruction in higher } \\
\text { education. }\end{array}$ & 32.3 & 35.5 & 21.0 & 11.3 & - \\
\hline $\begin{array}{l}\text { Benchmarking is not an appropriate tool for quality assurance in Higher } \\
\text { Education }\end{array}$ & 25.8 & 21.0 & 38.7 & 11.3 & 3.2 \\
\hline $\begin{array}{l}\text { There is too few academic staff to participate in benchmarking in my } \\
\text { programme/department. }\end{array}$ & 25.8 & 22.6 & 29.0 & 14.5 & 8.1 \\
\hline $\begin{array}{l}\text { Lack of time, money and expertise is a major constrain for not } \\
\text { benchmarking in my programme/department }\end{array}$ & 30.6 & 35.5 & 24.2 & 6.7 & 3.0 \\
\hline
\end{tabular}

The survey revealed that over $60 \%$ of the respondents were not aware of any benchmarking activities in their programme/department. Similarly, over $55 \%$ of the respondents agreed that they were not involved in many benchmarking activity in their department/school. Approximately $60 \%$ of the respondents felt benchmarking is more effective if it is initiated at grass root level rather than imposed by the organization. On average, $54 \%$ of the respondents 
agreed that benchmarking alone does not lead to quality of instruction in higher education, 50\% agreed that benchmarking is an appropriate tool for quality assurance in Higher Education, $48 \%$ indicated that they could not implement benchmarking because there was too few academic in their programme/department to participate in the activity. Over $70 \%$ felt lack of time, money and expertise is a major constrain for not benchmarking in their programme/department. From the findings, it is clear that there are a number of disincentives and problems that appears to impact on the effectiveness of benchmarking at the Central University of Technology. Such constraints may have a direct bearing on quality assurance in other Higher Education institutions in South Africa.

\section{Discussion}

The main objective of this study is to examine the effectiveness of benchmarking as a organizational transformation strategy in Higher Education institutions in South Africa in terms of (a) reasons for benchmarking (b) benefits for benchmarking and (c) disincentives and problems. The findings of this study were based on the answers to the three research questions: reasons for benchmarking; benefits for benchmarking and disincentives and problems.

Although benchmarking as a strategy for institutional reform in higher education, it has been an area of concern for many years. Analysis of the literature indicate that the managerial language in which much of benchmarking is couched, and the way the specific term 'benchmarking' is defined often conflict with the everyday use of the word within institutions. There are also difficulties in defining a distinction between benchmarking and quality assurance. Similarities between the two practices lie in ownership, learning and improvement and self- assessment. Benchmarking differs from quality assurance in many ways. It focus on learning from others, the exercise is voluntary, accountability not a priority, require setting institutional goals.

Holloway, Hinton and Mayle (1997) reported lack of commitment of academic staff as a major constraint in managing benchmarking process in higher education. Member of staff felt that their immediate concerns were not visibly going to be addressed, yet they are required to take on a significant new workload to make the exercise happen. Those undertaking benchmarking project are often faced with lack of collective responsibility. Block (2007) report that as the project is sometime belong to specialist area the head or coordinator is assumed to be responsible for benchmarking and no one else takes it as a personal or professional responsibility.

Regarding the reasons for benchmarking, the study found that the majority of the respondents did not use benchmarking to find how they were performing compared to other staff within their programme/department. A large percentage of the respondents were found to be unaware of the existence of benchmarking in their department and how it was being administered and by whom.

Benchmarking is found to increase the potential for improvement in numerous ways (Meade, 1997). In line with Meade (1997) assertion, the findings of this study revealed a large number of respondents who agree that benchmarking provides among other things: a systematic approach to quality improvement, establishes the extent of improvement required, bring an external focus to internal activities, enables the incorporation of 'best practice' into one's organization and promotes contacts and networks.

As regards disincentives and problems, the study found that only a small minority of respondents were involved in some form of benchmarking networking within and outside their programme/department. These findings were consistent to the findings of Holloway (1997) who reported that around $20 \%$ of the respondents were resistance to benchmarking or problems in implementing new ways of working. This type of problem may have wider implications, as benchmarking is in many ways less threatening than other approaches to performance improvement.

Williams, Brown, and Springer (2012) reported barriers to benchmarking and strategies to surmount these barriers. They concluded that organizational leadership best practices counter each of the four major benchmarking reluctance concerns: soundness of benchmarking theory/practices; lack of resources for benchmarking; inertia impeding pursuit of new practices; and specific impacts of implementing new practices.

\subsection{Limitations}

This study like any study is not without its limitations. First, the population sample was small given the lack of willingness of staff to participate in such as survey research. This factor could have affected the reliability of the research findings Secondly, the population from which the sample was selected consisted only of academic staff from one higher education institution. Selecting samples from only one university could have influenced the generalizability of the study's results; however, considering the fact that academic staff from across the four faculties does suggest that these results 
apply to all the faculties of the university.

Third, even though the alignment of benchmarking on the university Vision 2020 remained unexplored, the results of this study suggest that developing a clear policy on benchmarking is the first step in achieving organizational transformation in Higher Education institutions in South Africa. Despite the limitations, this research has highlighted several interesting areas for further studies. It is envisaged that this study will lead to further studies on the relationship between successful benchmarking and other approaches to performance improvement and the extent to which benchmarking is proving to be a cost effective paradigm.

\subsection{Conclusion}

This study has illustrated some of the challenges which higher education institutions face in using benchmarking as a strategy for organizational change, even when many features such as management capability and organizational culture are in their favour. This has important implications for higher education institutions in South Africa because the current policy direction is towards "best -practice" which unfortunately is influenced by a number of internal and external factors.

An indirect constribution which benchmarking could make such as organisation's capacity for succesful management of continual change is throgh providing appropriate process skills, often with relatively immediate oucomes to encaurage further activities. This line of reasoning (Bowerman and Ball, 2000) is appealing because it suggests that benchmarking might increase public sector organizations' responsiveness to stakeholder preferences, it fails to capture important complications that can be observed in practice. However, given the political environment in which higher education institutions operate, sometimes benchmarking might not have any effects on an institution's internal operations because it is used primarily as a means to defend rather than to improve performance.

While benchmarking may be viewed as a comprehensive method of helping organizations find, share and implement 'best practices' (Northcott and Llewellyn, 2005:423-424), it should not be seen as a panacea for organizationa change. It is most effective in the context of relatively small, but most important, process improvements. Its power perhaps increases as one moves towards process rather than results benchmarking. Research suggests that those organisations who gain most from benchmarking are also those who are effective at managing continual change and complexity in general.

\subsection{Recommendations}

Based on the research findings, the researcher proposes the following strategies for effective implementation of benchmarking in higher education institutions:

- If benchmarking is to work as a quality assurance tool it must be seen as part of the mainstream and core business of the institution, with all staff having a commitment to it

- Benchmarking appears to work best when it is conducted by an internal group to assist it in resolving a management problem or to position itself in its field of expertise.

- Need to be interpreted by professionals within the field rather than external consultants who has little knowledge of the details of the systems they are required to measure.

- Benchmarking exercise can produce useful results if it is used as a tool rather than as an end in itself

- Benchmarking process require full participation of all involved.

- It is recommended that, for benchmarking to achieve its intended objectives, the process should begin with a more "grassroots" level departmental or administrative project that measures best practices internally, or with local competitors.

- The overall goal is the adaption of the process enablers at the home institution to achieve effective quality improvement. Benchmarking is more than just gathering data. It involves adapting a new approach of continually questioning how processes are performed, seeking out best practices, and implementing new models of operation.

\section{References}

Alstete, J. W. (1996) Benchmarking in Higher Education: Adapting Best Practices To Improve Quality. ERIC Digest. Available at http://www.ericdigests.org/1997-3/bench.html

Alstete, J, W. (2004). Destination Benchmarking: Concepts, Practices and Operations Benchmarking: An International Journal, Vol. 11 Iss: 6 Emerald Group Publishing Limited 
Bhat, K.S (2002), "Total Quality Management" New Delhi, Himalayan Publishing House, New Delhi.

Bellingham, L. (2008). Quality assurance and the use of subject level reference point in the UK", Quality in Higher Education, 14(3):265276.

Camp, R.C. (1989), Benchmarking: The Search for Industry Best Practices That Lead to Superior Performance. Milwaukee, WI: ASQC Quality Press.

Camp, R.C. (1995). Business Process Benchmarking; Finding and Implementing Best Practices. Milwaukee, Wl: Quality Press.

David Gadenne, Bishnu Sharma, (2009) "An investigation of the hard and soft quality management factors of Australian SMEs and their association with firm performance", International Journal of Quality \& Reliability Management, 26(9): 865 - 880.

Ensor, P (2003). The National Qualifications Framework and higher education in South Africa: some epistemological issues, Journal of Education and Work, Journal of Education and Work 16(3): 325-346.

European Commission, Education and Training, (2007. The Lifelong Learning Programme 2007-2013, 2008, Glossary, available at http://ec.europa.eu/education/programmes/lip/guide/glossary_en.html

Gilder, G. (2012). Less developed countries (LDCs) facing higher education curricula reform challenges in a 'new world (dis)order' European Journal of Higher Education,1(20), iFirst article.

Harman, G (2004). New Directions in Internationalizing Higher Education: Australia's Development as an Exporter of Higher Education Services, Higher Education Policy , 17 pp.101-120.

Harvey, L and Williams, J (2010). Fifteen Years of Quality in Higher Education, Quality in Higher Education, 16(1): 3-36

HEQC, 2004.'Criteria for Institutional Audits', Pretoria, Council on Higher Education.

Holloway, J., Hinton, C. and Mayle, D. (1997). Why benchmark? Understanding the processes of best practice benchmarking. In: Business Track, British Academy of Management Conference, September 1997, London.

Holloway, J and Francis, G. (2002). Implications of subject benchmarking in the United Kingdom higher education: The case of business and management', Quality in Higher Education 8(3):239-253.

Kempner, D.E. (1993). The Pilot Years: The Growth of the NACUBO Benchmarking Project. NACUBO Business Officer, 27(6), 21-31.

Mancuso, S. (2001). Adult-centred Practices: Benchmarking studies in Higher Education. Innovative Higher Education (25(3):165-181.

Marginson, S. (2007). The public/private divide in higher education: A global revision. Higher Education 53(3):307-333.

Meek, V.L. (2002) International Higher Education and the Role of Government in Educational Exports, Consultancy Report Prepared for DEST, Armidale, Centre for Higher Education Management and Policy, University of New England.

Mehraj Ud Din Shah, (2012). Benchmarking in Business Education: An Exploratory Study Indian Streams Research Journal 1(12)

Moore, M and Lan Lin, P (Eds.) (2009) Service Learning in Higher Education: Paradigms \& Challenges, University of Indianapolis Press.

Nazarko, J.,A.K. Kuzmicz, E. Szubzda-Prutis, and J. Urban. (2009). The general concept of benchmarking and its application in higher education in Europe. Higher Education in Europe 34(3): 497-510.

Nicholson, K. (2011). Quality assurance in higher education: A review of the literature. Retrieved June 182012 ,from: http:/cll.mcmater.ca/COU/pdf/Quality\%20Assurance\%20Literature\%20Review.pdf\#search=\%22Australia+Higher+Education+gre ater+accountability\%22. Salmi, J. and Saroyan, A. (2007). League tables as policy instruments: Uses and misuses. Higher Education Management and Policy 19(2):31-68.

Rashmi Jain, Anithashree Chandrasekaran, Angappa Gunasekaran, (2010) "Benchmarking the redesign of "business process reengineering" curriculum: A continuous process improvement (CPI)", Benchmarking: An International Journal, Vol. 17(1):77-94

Salmi, J. and Saroyan, A. (2007). League tables as policy instruments: Uses and misuses. Higher Education Management and Policy 19(2):31-68.

Shafer, B.S., \& Coate, L.E. (1992). Benchmarking in Higher Education: A Tool for Improving Quality and Reducing Cost. Business Officer, 26(5), 28-35.

Scott, R (2011). ECU Benchmarking Policy (Edith Cowan University, 2011) and Benchmarking Guidelines. Retrieved on 18 June 2912 from http://www.ecu.edu.au/GPPS/policies_db/tmp/ac080.pdf Ellibee

UNESCO (1998). A study conducted by the Commonwealth Higher Education Management Service, Paris France.

UNESCO (2001). The impact of globalisation on quality assurance, accreditation and the recognition of qualifications in higher education' Paris, France UNESCO Publication. Retrieved on 214 April 2012 from: http://www.unesco.org/education /studyingabroad/highlights/global_forum/expert_main.shtml.

Van der Bijl, Andre; Ebrahim, Adele (2012) Centres of excellence in the context of further education and training in South Africa. Industry and Higher Education, 26 (1):53-62(10)

Weeks, P. (2000). Benchmarking in Higher Education: An Australian Case study: Innovations in Education and Training International 37(1):59-67.

Williams, J.,Brown, C. and Springer, A. (2012) "Overcoming benchmarking reluctance: a literature review", Benchmarking: An International Journal,19(I2): $255-276$.

Woolf, H., Cooper, A., Bourdillon, B., Bridges, P., Collymore, D., Haines, C., Turner, D. and Yorke, M. (1999). Benchmarking academic standards in history: An empirical exercise', Quality in Higher Education, 5(2):145-154.

You-chi Hou, A (2012). Impact of excellence programmes on Taiwan higher education in terms of quality assurance and academic excellence, examining the conflicting role of Taiwan's role of Taiwan's accrediting agencies. Asia pacific Education Review, Vol.13:77-88. 
Zeinalnezhad, M, Mukhtar, M., Shahnorbanun Sahran, S. (2011). A Study on Benchmarking Models and Frameworks in Industrial SMEs: Challenges and Issues. Proceeding of the International Conference on Advanced Science, Engineering and Information Technology 2011 Hotel Equatorial Bangi-Putrajaya, Malaysia, 14 - 15 January 2011 